\title{
An analytic hierarchy process model for selecting adsorbent for heavy metal ion removal from wastewater
}

\author{
Shereen Ababneh'1, Omar Al-Araidah' and Mohammed Almomani' \\ 'Industrial Engineering Department, Jordan University of Science and Technology, Irbid, 22110, Jordan
}

This paper provides an analytic hierarchy process (AHP) model for the selection of an adsorbent to adhere with multiple types of metal ions from wastewater. Experimental literature is surveyed to estimate the entries for comparison matrices. The model allows the user to combine the degree of importance of the adsorption of each ion type to the degree of importance of both technical and non-technical criteria. A case study is provided to select among three adsorbents and three types of ions. Results illustrate the usability of the model in handling experimental problems; chitosan is selected for its high technical qualities, that sludge is preferred for its availability and low cost, and that $\mathrm{pH}$-level and adsorbent-dosage are the most influential sub-criteria to control to enhance adsorption efficiency. Moreover, sensitivity analysis shows that the decision is impacted by the relative importance of technical criteria and by the degree of importance of ions.

\section{INTRODUCTION}

Industrial wastewater containing heavy metal ions is considered a major threat to human life and the environment worldwide for its high level of toxicity. Several methods are used for wastewater treatment and the disposal of heavy metals. Such methods include chemical and physical precipitation, reverse osmosis, ion exchange, membrane filtration, adsorption, solvent extraction and electrochemical treatment (Burakov et al., 2018).

The removal of heavy metal ions from wastewater by adsorption has been widely documented in the literature. Ion adsorption from water is the adhesion of ions in water to the surface of the adsorbent. Advantages of wastewater treatment by adsorption include availability at low cost, ease of use, efficiency in ion removal, reduced waste, and reversibility that allows the reuse of adsorbent and metal ions (Ariffin et al., 2017). Several authors have investigated the efficiency of using various types of adsorbents in removing selected metal ions from wastewater under different values of study parameters, including the initial concentration of metal ions (Abdel-Ghani and El-Chaghaby, 2014), types of ions (Hui et al., 2005), adsorbent dosage (Burakov et al., 2018), contact time (Hui et al., 2005), pH level (Bisht et al., 2016) and temperature (Al-Zboon et al., 2011). In addition, authors have discussed the influence of cost and availability of the adsorbent as key decision factors that justify the use of naturally available adsorbents (Bisht et al., 2016).

Several authors have reviewed the relevant literature. Farooq et al. (2010) reviewed literature on the utilization of straw and bran for the removal of metal ions from wastewater. The authors investigated the influences of change in temperature and $\mathrm{pH}$ level on metal biosorption by wheat straw and wheat bran. Literature shows that the biosorption mechanism comprises a number of phenomena, including adsorption, surface precipitation, ion-exchange and complexation. It was found that wheat straw and wheat bran are economical alternatives for metal removal due to their high efficiency, high biosorption capacity, cost-effectiveness and renewability. Abdel-Ghani and El-Chaghaby (2014) presented a review on using non-modified bio-sorbents, include biomass materials, for removal of metal ions from wastewater under several influencing factors, such as: $\mathrm{pH}$ level, metal ion concentration, biomass dose and contact time. Results show that biomass materials positively contribute to the biosorption of metal ions. The removal of metal ions increases by increasing the solution $\mathrm{pH}$ up to a certain limit and is almost negligible at highly acidic $\mathrm{pH}$ values. Moreover, the biosorption capacity increases as the initial concentration of metal ion in the solution increases, but is reduced when the biomass dosage increases. Bisht et al. (2016) provided a review of literature on commercially available and agricultural adsorbents used for removing selected heavy metal ions from wastewater. Study criteria included $\mathrm{pH}$ level, contact time, adsorbent dosage, temperature, \% removal, cost, availability and metal concentration. Results show that performance of agricultural adsorbents is comparable to commercially available adsorbents, but at lower cost. Moreover, agricultural adsorbents are widely available and generate no sludge. Ariffin et al. (2017) presented a review on using a geopolymer in adsorption of heavy metal ions from aqueous solution under various $\mathrm{pH}$ levels, adsorbent dosage, initial concentration, contact time and temperature. The results show that fly ash is the most effective geopolymer material in removing metal ions from wastewater, due to its availability and cheapness. Moreover, increasing adsorbent dosage, contact time and initial concentration will increase the adsorption capacity. Burakov et al. (2018) provided a review on the removal of heavy metal ions from different water solutions using several adsorbent materials, including conventional (activated carbons, zeolites, clays, bio-adsorbents, industrial by-products, etc.),
CORRESPONDENCE

Omar Al-Araidah

EMAIL

alarao@just.edu.jo

\section{DATES}

Received: 21 July 2019

Accepted: 12 June 2020

\section{KEYWORDS}

MCDM

AHP

selection

adsorption

heavy metal ions

wastewater

\section{COPYRIGHT}

(c) The Author(s)

Published under a Creative

Commons Attribution 4.0

International Licence

(CC BY 4.0) 
and original and functionalized nanostructures (fullerenes, carbon nanotubes, graphene, graphene oxide), under several values for $\mathrm{pH}$ level, temperature, initial concentration, adsorbent dose and contact time. Results show that using nanostructured adsorbents increased maximum sorption capacity in a shorter time compared to the conventional materials. Other studies experimentally investigated the performance of adsorbents under the various study parameters. Studied adsorbents include raw kaolinite (Yavuz et al., 2003), zeolite 4A (Hui et al., 2005), geopolymers (Al-Zboon et al., 2011), peanut husk charcoal, fly ash and natural zeolite (Abdel Salam et al., 2011), biochar (Inyang et al., 2012) and microcrystalline bisphosphonate material (N10O) (Turhanen et al., 2015).

Selection among the various types of adsorbents is a multiplecriteria decision-making (MCDM) problem that can be solved using several tools, including analytic hierarchy process (AHP), fuzzy logic, technique for order of preference by similarity to ideal solution (TOPSIS), weighted sum model (WSM), and combinations of more than one method. Omasa et al. (2004) used AHP to select a chemical reactor for tissue engineering and regenerative medicine. Venkataramaiah et al. (2012) utilized an AHP model to choose the best material for a solar plate collector. To the best of our knowledge, no literature exists on utilizing any of these methods to select among adsorbents. This study provides a generic AHP-MCDM model for selecting adsorbent material for the removal of multiple heavy metal ions from wastewater based on technical and non-technical criteria.

\section{METHODS}

\section{Selection criteria}

Literature was consulted to identify criteria used to select the better adsorbent material for the removal of heavy metal ions from wastewater, and experts from academia were interviewed to recognize the degree of significance of decision criteria. Only significant criteria were used for pairwise comparisons. Table 1 summarizes criteria and sub-criteria utilized in this research.

For the purpose of this study, 'Type of metal ions' present in wastewater is not considered among the technical sub-criteria in the model to allow for evaluation of alternatives for various types of metal ions.

Table 1. Main criteria for heavy metal ion removal from wastewater

\begin{tabular}{ll}
\hline Criteria (C) & Sub-criteria (CS) \\
\hline $\mathrm{C}_{1}:$ & $\mathrm{CS}_{11}: \mathrm{pH}$ level \\
Technical & The initial acidity or basicity of wastewater
\end{tabular}

$\mathrm{CS}_{12}$ : Concentration of heavy metal ions:

The amount of ion in a given volume of wastewater

$\mathrm{CS}_{13}$ : Contact time

The duration of adsorption measured in hours, minutes and seconds

$\mathrm{CS}_{14}$ : Temperature

The initial temperature of wastewater in ${ }^{\circ} \mathrm{C}$ or ${ }^{\circ} \mathrm{F}$, or K

$\mathrm{CS}_{15}:$ Adsorbent dosage

Amount of adsorbent added to wastewater

Type of metal ions

The variety of metal ions presented in wastewater

$\mathrm{C}_{2}: \quad \mathrm{CS}_{21}:$ Cost

Non-technical The dollar expense of using a certain amount of the adsorbent

$\mathrm{CS}_{22}$ : Availability

The ease of accessibility to the adsorbent

\section{The AHP hierarchical structure}

Figure 1 illustrates the hierarchical structure of the proposed AHP model for selecting a better adsorbent material for removing ions of heavy metals from wastewater.

The pairwise comparisons are constructed for the various levels of the AHP hierarchy to obtain the relative importance of criteria, sub-criteria and alternatives with respect to each sub-criterion. In a comparison matrix, the intersection between a row and column represents the relative importance of the row criteria compared to the column criteria using a numeric based on the Saaty scale. To calculate the weights for the criteria in a comparison matrix, a normalized matrix is built by dividing each element in a column by the summation of all elements in that column. For each row, the summation of all elements in that row is computed resulting in a new column of summations. Then, each element in the new column of summations of rows is divided by the number of criteria. The principles for building the matrices and basic calculations can be found in Chang et al, (2007).

Using computed weights for sub-criteria, $W_{\mathrm{CS} 11}$ to $W_{\mathrm{CS} 15}$ and $W_{\mathrm{CS} 21}$ and $W_{\mathrm{CS22}}$, and the scores of each adsorbent alternative $l$ at each sub-criteria, $\mathrm{S}_{1}\left(\mathrm{CS}_{11}\right)$ to $\mathrm{S}_{1}\left(\mathrm{CS}_{15}\right)$ and $\mathrm{S}_{1}\left(\mathrm{CS}_{21}\right)$ and $\mathrm{S}_{1}\left(\mathrm{CS}_{22}\right)$, the total score for alternative adsorbent $l$ can be obtained as the sum in Eq. 1.

$$
S_{l}=\sum_{j=1}^{5} S_{l}\left(\mathrm{CS}_{1 j}\right) W_{\mathrm{CS} 1 j}+\sum_{j=1}^{2} S_{l}\left(\mathrm{CS}_{2 j}\right) W_{\mathrm{CS} 2 j}
$$

The best alternative adsorbent is then the alternative with the highest final score $S$.

To account for the removal of multiple ions with different degrees of importance, the total scores of alternatives are manipulated such that both scores on technical and non-technical criteria are adjusted by the degree of importance of ion type, as in Eq. 2 . Alternatively, the total scores of alternatives are manipulated such that only scores on technical criteria are adjusted by the relative importance of ion type as in Eq. 3.

$$
\begin{gathered}
S_{l}=\sum_{\text {Ion }=1}^{I}\left(S_{l \text { Tech }}+S_{l \text { Non-Tech }}\right)_{\text {Ion }} W_{\text {Ion }} \\
S_{l}=\sum_{\text {Ion }=1}^{I}\left(S_{l \text { Tech }}\right)_{\text {Ion }} W_{\text {Ion }}+\left(S_{l \text { Non-Tech }}\right)_{\text {Ion }}
\end{gathered}
$$

\section{CASE STUDY}

The case study handles the removal of three heavy metal ions, namely, lead $(\mathrm{Pb})$, copper $(\mathrm{Cu})$ and nickel $(\mathrm{Ni})$, from wastewater originating from industrial activities that release toxic ions, disposal of products containing them such as batteries and paints, and from natural sources such as volcanoes and hot springs. Many researchers have investigated the use of several adsorbents to remove lead, copper and nickel ions from wastewater efficiently. Adsorbents include natural adsorbents such as wheat bran, sludge, rice husk and fruits peels, by-product adsorbents such as fly ash and sawdust, and synthesized adsorbents like activated carbon and graphene (Kaur and Sharma, 2017). For the purposes of this research, chitosan, fly ash and sludge adsorbent materials were considered. A complete review of the literature was done and the performance of each of the selected adsorbents for the removal of lead, copper and nickel under different values of the study parameters was summarised. Inputs were then aggregated and a customized Excel AHP model was constructed to obtain the results and perform a sensitivity analysis. 


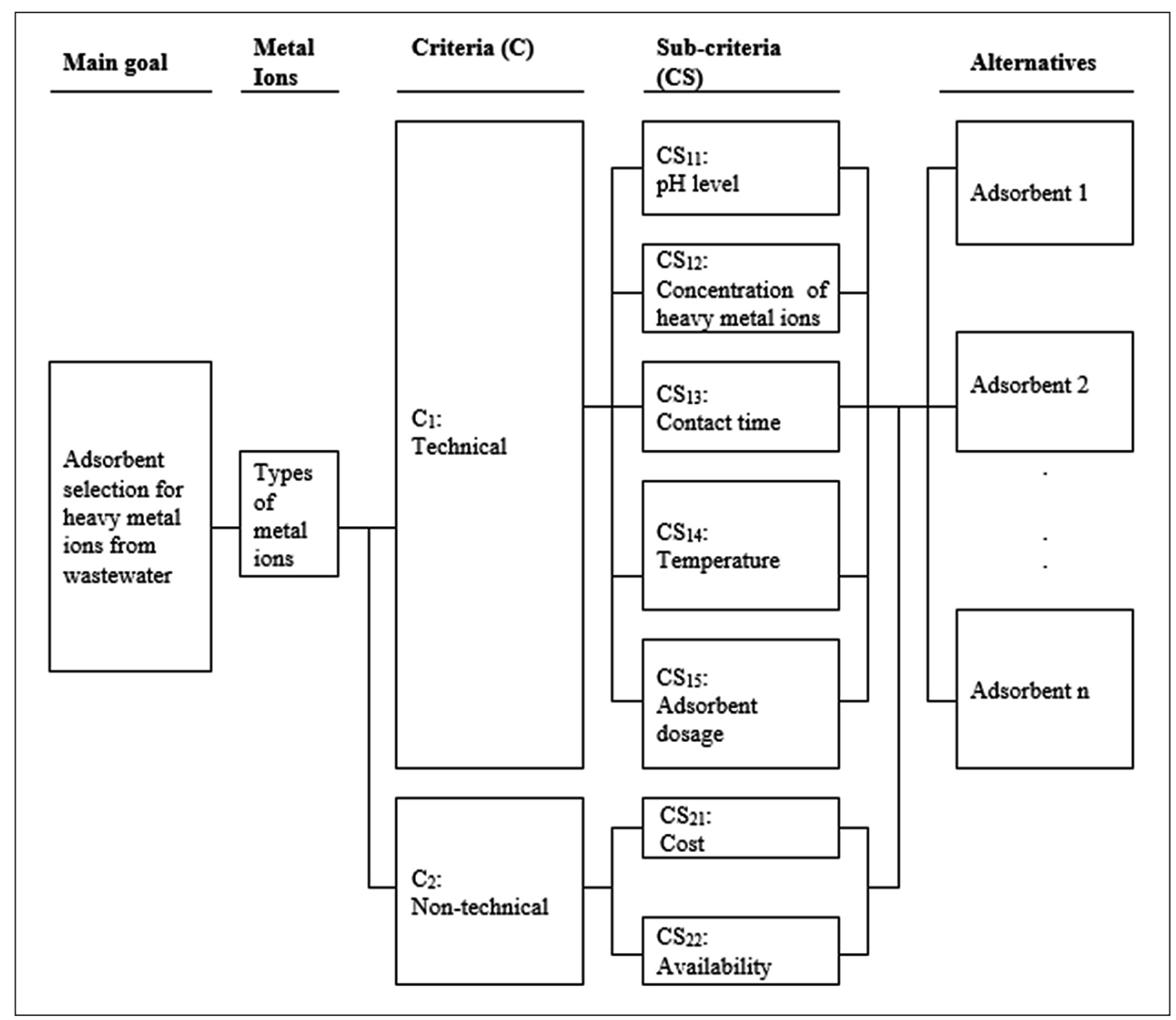

Figure 1. Hierarchical structure to select the adsorbent material for the removal of heavy metal ions from wastewater

\section{Estimating entries for technical matrices}

Experts can be consulted to estimate entries for the pairwise comparison matrices. The relative importance of a sub-criteria 'a' with respect to another sub-criteria 'b' represents the increase in percentage of adsorption uptake if sub-criteria 'a' is optimized compared to if sub-criteria ' $b$ ' is optimized. Alternatively, the relative importance between pairs of sub-criteria can be determined based on published experimental literature on the performance of each adsorbent in removing specific heavy metal ions. For example, Kaur and Sharma (2017) reviewed and summarized experimental results of ion removal using various adsorbents at different levels of $\mathrm{pH}$, ion concentration, temperature, contact time, ion type and adsorbent dosage. Listed improvements can then be used as a basis for estimating the relative importance in pairwise comparison matrices based on the Saaty scale. The following example illustrates the estimation of relative importance between $\mathrm{pH}$ level and temperature. Increasing the $\mathrm{pH}$ level from 3 to 4 increases uptake efficiency by $50 \%$. On the other hand, increasing temperature from $35^{\circ} \mathrm{C}$ to $45^{\circ} \mathrm{C}$ increases uptake efficiency by $3 \%$. Therefore, a Saaty numeric of 9 can be safely assigned to show the relative superiority of $\mathrm{pH}$ compared to temperature.

In this study, the literature was surveyed to estimate entries that were later used to fill the pairwise comparison matrices of technical sub-criteria and the performance of adsorbent alternatives over technical sub-criteria. Related entries were estimated by comparing the values of percentage uptake for the different adsorbents and ions in the experimental literature. On the other hand, logic was used to estimate other entries for degree of importance of ions, importance of technical criteria relative to non-technical criteria, relative importance of non-technical subcriteria and relative performance of adsorbent alternatives over non-technical sub-criteria. Sensitivity analysis over the full range of the Saaty scale was then utilized to test changes in decisions based on logical entries.

The varying percentages of uptake of an ion reported in the literature suggest that an estimate for an entry will not be optimal for all the types of adsorbents. Hence, pairwise comparison matrices of technical criteria are constructed for each ion type such that several experimental entries are averaged and the closest Saaty numeric is recorded to obtain the closest estimate for each entry, such that matrix consistency condition is preserved. This results in a comparison matrix in which percentage uptake as a result of varying values of a sub-criterion is independent of other sub-criteria and independent of the type of adsorbent. It is worth mentioning here that for each sub-criterion, the percentage uptake over the range from minimum to optimal level of the sub-criterion is considered. For example, studies investigated the impact of $\mathrm{pH}$ level ranging from acid to neutral (water); $\mathrm{pH}$ level was considered because moving to $\mathrm{pH}$ levels that are basic negatively impacts the percentage uptake. Figure 2 shows a summary of all estimates entered into Excel for the AHP computations. Ion 1, Ion 2 and Ion 3 represent lead, copper and nickel, respectively. Alt1, Alt2 and Alt3 are chitosan, fly ash and sludge, respectively. For example, literature suggests that the $\mathrm{pH}$ level of wastewater is absolutely more important in removing lead ions than the initial concentration, and hence a numeric of 9 is assigned to that entry. Studies have shown a high impact from normalizing the acidity of wastewater (increasing $\mathrm{pH}$ level from 2 to 6 ) in improvement of the efficiency of the adsorption process, while increasing the concentration of lead ions in wastewater has a negative effect on the efficiency of the adsorption process. Similarly, studies have reported that fly ash (Alt2) and sludge (Alt3) perform similarly in the removal of lead ions (Ion 1) as the $\mathrm{pH}$ level (SC11) changes while chitosan (Alt1) performs better than both of them as $\mathrm{pH}$ level changes. 


\begin{tabular}{|c|c|c|c|c|c|c|c|c|c|c|c|c|c|c|c|c|c|c|c|}
\hline \multicolumn{5}{|c|}{ Relative Importance of Ions } & \multicolumn{4}{|c|}{ Main Criteria } & \multicolumn{3}{|c|}{ Non Technical criteria } & \multicolumn{8}{|c|}{ Alternatives for Non Technical Criteria } \\
\hline & Ion 1 & Ion 2 & Ion 3 & & & $\mathrm{C} 1$ & $\mathrm{C} 2$ & & & $\mathrm{CS}_{21}$ & $\mathrm{CS}_{22}$ & CS21 & Alt1 & Alt2 & Alt3 & CS22 & Alt1 & Alt2 & Alt3 \\
\hline Ion 1 & 1 & 0.2 & 0.333 & & $\mathrm{C} 1$ & 1 & 3 & & $\mathrm{CS}_{21}$ & 1 & 5 & Alt1 & 1 & 0.2 & 0.111 & Alt1 & 1 & 0.333 & 0.111 \\
\hline Ion 2 & 5 & 1 & 3 & & $\mathrm{C} 2$ & 0.333 & 1 & & $\mathrm{CS}_{22}$ & 0.2 & 1 & Alt2 & 5 & 1 & 0.333 & Alt2 & 3 & 1 & 0.333 \\
\hline \multirow[t]{2}{*}{ Ion 3} & 3 & 0.333 & 1 & & & CR & 0.000 & & & CR & 0.000 & Alt3 & 9 & 3 & 1 & Alt3 & 9 & 3 & 1 \\
\hline & & CR & 0.048 & & & & & & & & & & & $\mathrm{CR}$ & 0.039 & & & $\mathrm{CR}$ & 0.000 \\
\hline \multicolumn{8}{|c|}{ Technical criteria for lon 1} & \multicolumn{12}{|c|}{ Alternatives for lon 1} \\
\hline Ion 1 & $\mathrm{CS}_{11}$ & $\mathrm{CS}_{12}$ & $\mathrm{CS}_{13}$ & $\mathrm{CS}_{14}$ & $\mathrm{CS}_{15}$ & & & CS11 & Alt1 & Alt2 & Alt3 & CS12 & Alt1 & Alt2 & Alt3 & CS13 & Alt1 & Alt2 & Alt3 \\
\hline $\mathrm{CS}_{11}$ & 1 & 9 & 3 & 3 & 1 & & & Alt1 & 1 & 5 & 3 & Alt1 & 1 & 1 & 1 & Alt1 & 1 & 0.333 & 5 \\
\hline $\mathrm{CS}_{12}$ & 0.111 & 1 & 0.143 & 0.143 & 0.111 & & & Alt2 & 0.2 & 1 & 1 & Alt2 & 1 & 1 & 1 & Alt2 & 3 & 1 & 7 \\
\hline $\mathrm{CS}_{13}$ & 0.333 & 7 & 1 & 3 & 0.333 & & & Alt3 & 0.333 & 1 & 1 & Alt3 & 1 & 1 & 1 & Alt3 & 0.2 & 0.143 & 1 \\
\hline $\mathrm{CS}_{14}$ & 0.333 & 7 & 0.333 & 1 & 0.2 & & & & & CR & 0.037 & & & $\mathrm{CR}$ & 0.000 & & & $\mathrm{CR}$ & 0.083 \\
\hline \multirow[t]{5}{*}{$\mathrm{CS}_{15}$} & 1 & 9 & 3 & 5 & 1 & & & CS14 & Alt1 & Alt2 & Alt3 & CS15 & Alt1 & Alt2 & Alt3 & & & & \\
\hline & & & & CR & 0.086 & & & Alt1 & 1 & 7 & 9 & Alt1 & 1 & 7 & 7 & & & & \\
\hline & & & & & & & & Alt2 & 0.143 & 1 & 1 & Alt2 & 0.143 & 1 & 1 & & & & \\
\hline & & & & & & & & Alt3 & 0.111 & 1 & 1 & Alt3 & 0.143 & 1 & 1 & & & & \\
\hline & & & & & & & & & & CR & 0.012 & & & $C R$ & 0.000 & & & & \\
\hline \multicolumn{8}{|c|}{ Technical criteria for lon 2} & \multicolumn{12}{|c|}{ Alternatives for Ion 2} \\
\hline Ion 2 & $\mathrm{CS}_{11}$ & $\mathrm{CS}_{12}$ & $\mathrm{CS}_{13}$ & $\mathrm{CS}_{14}$ & $\mathrm{CS}_{15}$ & & & CS11 & Alt1 & Alt2 & Alt3 & CS12 & Alt1 & Alt2 & Alt3 & CS13 & Alt1 & Alt2 & Alt3 \\
\hline $\mathrm{CS}_{11}$ & 1 & 9 & 1 & 5 & 3 & & & Alt1 & 1 & 9 & 5 & Alt1 & 1 & 0.2 & 0.333 & Alt1 & 1 & 3 & \begin{tabular}{|l|}
0.333 \\
\end{tabular} \\
\hline $\mathrm{CS}_{12}$ & \begin{tabular}{|l|}
0.111 \\
\end{tabular} & 1 & \begin{tabular}{|l|} 
\\
\end{tabular} & \begin{tabular}{|l|}
0.111 \\
\end{tabular} & 0.143 & & & Alt2 & \begin{tabular}{|l|}
0.111 \\
\end{tabular} & 1 & 0.33 & Alt2 & 5 & 1 & 3 & Alt2 & 0.333 & 1 & 0.2 \\
\hline $\mathrm{CS}_{13}$ & 1 & 9 & 1 & 3 & 1 & & & Alt3 & 0.2 & 3 & 1 & Alt3 & 3 & 0.333 & 1 & Alt3 & 3 & 5 & 1 \\
\hline $\mathrm{CS}_{14}$ & 0.2 & 9 & \begin{tabular}{|l|}
0.333 \\
\end{tabular} & 1 & 0.333 & & & & & $C R$ & 0.045 & & & $C R$ & 0.048 & & & $C R$ & 0.048 \\
\hline \multirow[t]{5}{*}{$\mathrm{CS}_{15}$} & \begin{tabular}{|l|}
0.333 \\
\end{tabular} & 7 & 1 & 3 & 1 & & & CS14 & Alt1 & Alt2 & Alt3 & CS15 & Alt1 & Alt2 & Alt3 & & & & \\
\hline & & & & CR & 0.097 & & & Alt1 & 1 & 9 & 9 & Alt1 & 1 & 9 & 5 & & & & \\
\hline & & & & & & & & Alt2 & 0.111 & 1 & 1 & Alt2 & 0.111 & 1 & 0.333 & & & & \\
\hline & & & & & & & & Alt3 & \begin{tabular}{|l|}
0.111 \\
\end{tabular} & 1 & 1 & Alt3 & 0.2 & 3 & 1 & & & & \\
\hline & & & & & & & & & & $C R$ & 0.000 & & & $C R$ & 0.045 & & & & \\
\hline \multicolumn{8}{|c|}{ Technical criteria for lon 3} & \multicolumn{12}{|c|}{ Alternatives for lon 3} \\
\hline Ion 3 & $\mathrm{CS}_{11}$ & $\mathrm{CS}_{12}$ & $\mathrm{CS}_{13}$ & $\mathrm{CS}_{14}$ & $\mathrm{CS}_{15}$ & & & CS11 & Alt1 & Alt2 & Alt3 & CS12 & Alt1 & Alt2 & Alt3 & CS13 & Alt1 & Alt2 & Alt3 \\
\hline $\mathrm{CS}_{11}$ & 1 & 9 & 5 & 9 & 1 & & & Alt1 & 1 & 3 & 3 & Alt1 & 1 & 5 & 0.333 & Alt1 & 1 & 1 & 0.2 \\
\hline $\mathrm{CS}_{12}$ & 0.111 & 1 & 0.333 & 0.333 & 0.111 & & & Alt2 & 0.333 & 1 & 1 & Alt2 & 0.2 & 1 & 0.143 & Alt2 & 1 & 1 & 0.143 \\
\hline $\mathrm{CS}_{13}$ & 0.2 & 3 & 1 & 5 & 0.2 & & & Alt3 & \begin{tabular}{|l|}
0.333 \\
\end{tabular} & 1 & 1 & Alt3 & 3 & 7 & 1 & Alt3 & 5 & 7 & 1 \\
\hline $\mathrm{CS}_{14}$ & 0.111 & 3 & 0.2 & 1 & 0.111 & & & & & $C R$ & 0.064 & & & $\mathrm{CR}$ & 0.083 & & & $\mathrm{CR}$ & 0.019 \\
\hline \multirow[t]{5}{*}{$\mathrm{CS}_{15}$} & 1 & 9 & 5 & 9 & 1 & & & CS14 & Alt1 & Alt2 & Alt3 & CS15 & Alt1 & Alt2 & Alt3 & & & & \\
\hline & & & & $C R$ & 0.099 & & & Alt1 & 1 & 5 & 7 & Alt1 & 1 & 0.333 & 5 & & & & \\
\hline & & & & & & & & Alt2 & 0.2 & 1 & 1 & Alt2 & 3 & 1 & 9 & & & & \\
\hline & & & & & & & & Alt3 & 0.143 & 1 & 1 & Alt3 L & 0.2 & 0.111 & 1 & & & & \\
\hline & & & & & & & & & & $C R$ & 0.019 & & & $C R$ & 0.039 & & & & \\
\hline
\end{tabular}

Figure 2. Summary of all estimates as entered into Excel for AHP computations

Table 2. Summary of results for adsorbent selection for wastewater contaminated with one type of ion

\begin{tabular}{|c|c|c|c|c|c|c|c|c|c|c|c|c|c|c|c|c|}
\hline & \multicolumn{7}{|c|}{ Synthesis weights (SW) } & \multicolumn{3}{|c|}{ Score (tech) } & \multicolumn{3}{|c|}{ Score (non-tech) } & \multicolumn{3}{|c|}{ Total score } \\
\hline & $\mathrm{CS}_{11}$ & $\mathrm{CS}_{12}$ & $\mathrm{CS}_{13}$ & $\mathrm{CS}_{14}$ & $\mathrm{CS}_{15}$ & $\mathrm{CS}_{21}$ & $\mathrm{CS}_{22}$ & Alt1 & Alt2 & Alt3 & Alt1 & Alt2 & Alt3 & It1 & Alt2 & Alt3 \\
\hline Ion 1 & 0.249 & 0.021 & 0.126 & 0.080 & 0.279 & 0.208 & 0.042 & 0.483 & 0.166 & 0.101 & 0.016 & 0.065 & 0.116 & 0.499 & 0.232 & 0.269 \\
\hline $\operatorname{lon} 2$ & 0.283 & 0.021 & 0.203 & 0.086 & 0.157 & 0.208 & 0.042 & 0.455 & 0.074 & 0.221 & 0.016 & 0.065 & 0.116 & 0.471 & 0.139 & 0.390 \\
\hline Ion 3 & 298 & 0.026 & 0.087 & 0.041 & 0.298 & 0.208 & 0.042 & 0.308 & 0.277 & 0.165 & 0.016 & 0.065 & 0.116 & 0.325 & 0.342 & 0.333 \\
\hline
\end{tabular}

Table 3. Sample results for impact of criteria adjustment method on the selection of adsorbent for wastewater contaminated with all three types of ions

\begin{tabular}{|c|c|c|c|c|c|c|c|c|c|c|}
\hline & \multirow{2}{*}{$\begin{array}{c}\text { Degree of } \\
\text { importance of ions }\end{array}$} & \multirow[t]{2}{*}{ Alt } & \multicolumn{4}{|c|}{ Method 1} & \multicolumn{4}{|c|}{ Method 2} \\
\hline & & & Ion 1 & Ion 2 & Ion 3 & Total & Ion 1 & Ion 2 & Ion 3 & Total \\
\hline Ion 1 & 0.106 & Alt1 & 0.053 & 0.298 & 0.085 & 0.436 & 0.068 & 0.304 & 0.097 & 0.313 \\
\hline Ion 2 & 0.633 & Alt2 & 0.025 & 0.088 & 0.089 & 0.202 & 0.083 & 0.112 & 0.137 & 0.222 \\
\hline Ion 3 & 0.260 & Alt3 & 0.029 & 0.247 & 0.087 & 0.362 & 0.179 & 0.308 & 0.211 & 0.466 \\
\hline
\end{tabular}

\section{Results and sensitivity analysis}

Tables 2 and 3 summarize the results obtained from Excel for AHP initial computations. Table 2 shows the results for wastewater contaminated with one type of ion. Results show that adsorbent dosage $\left(\mathrm{CS}_{15}\right)$ is the most important sub-criterion (0.274) to control to enhance the removal of lead ions from wastewater, and chitosan (Alt 1) is the best adsorbent for the removal of lead ions from wastewater, based on estimated entries with a total score of 0.499 . Moreover, if wastewater is contaminated with copper ions only, $\mathrm{pH}$ level $\left(\mathrm{CS}_{11}\right)$ is the most important sub-criterion, and chitosan (Alt1) is the best adsorbent for the removal of copper ions from wastewater. Furthermore, if wastewater is contaminated with nickel ions only, $\mathrm{pH}$ level $\left(\mathrm{CS}_{11}\right)$ and adsorbent dosage $\left(\mathrm{CS}_{15}\right)$ are the most important sub-criteria, and fly ash (Alt2) is the best adsorbent for the removal of nickel ions from wastewater based on estimated entries with a total score of 0.342 . Table 3 summarizes the results for wastewater contaminated with all three types of ions, with importance degrees of removal of ions of $0.106,0.633$ and 0.260 for $\mathrm{Pb}, \mathrm{Cu}$ and $\mathrm{Ni}$, respectively. Results show that if both technical and non-technical criteria are adjusted by the relative importance of ions (Method 1), chitosan (Alt1) scored highest (0.436), making it the best adsorbent to remove the three ions based on estimated entries. On the other hand, if only technical criteria are adjusted by the relative importance of ions (Method 2), sludge (Alt3) is selected, with a score of 0.466 , as the best alternative, since it is the most readily available and cheapest adsorbent. 
Table 4. Summary of results for various inputs of relative importance of technical versus non-technical criteria and that of ions

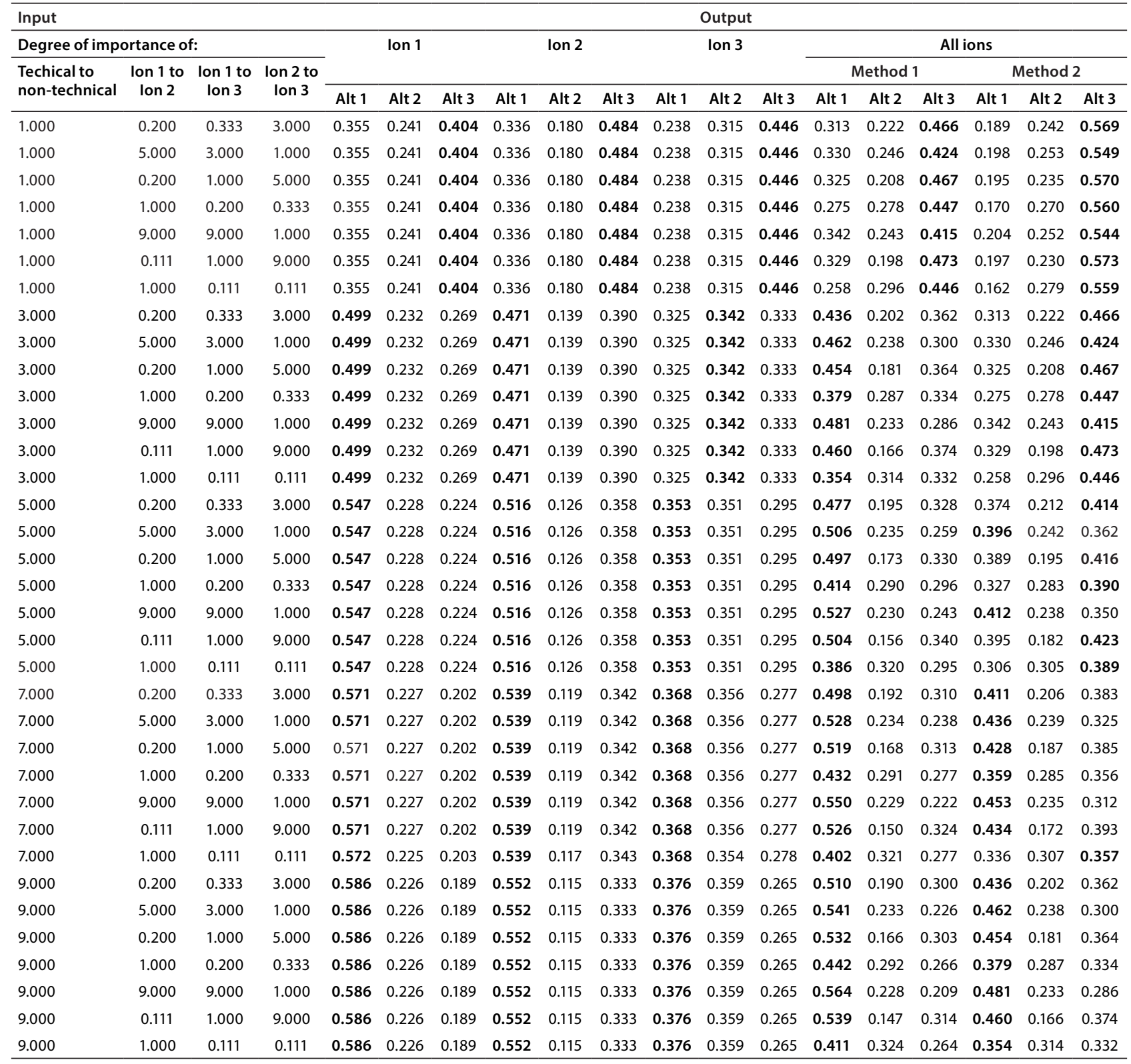

Sensitivity analysis shows that the decision is highly impacted by the relative importance of technical criteria vs non-technical criteria for various combinations of degrees of importance of ions. Moreover, results vary based on the absolute importance of ions, when technical criteria are more important and strongly more important than non-technical criteria. Table 4 shows a summary of results under different combinations of inputs using both methods of adjustment. For the purpose of this study, variations were investigated based on likely controllable inputs of the decision maker, including the degree of importance of technical criteria relative to non-technical criteria and the relative importance of removing each ion type with respect to other ions. It should be noted that since entries of matrices of technical sub-criteria were obtained from experimental literature, no changes to inputs were performed since this requires experimental validation. Moreover, only exact Saaty scale numeric values of 1, 3, 5, 7 and 9 were used for entries. Results for the best adsorbent alternative for each scenario are presented in bold in Tables 2, 3 and 4 .

The following scenarios illustrate some of the results. If the relative importance of ions changed such that the scores of ions are 0.633 , 0.106 and 0.260 for $\mathrm{Pb}, \mathrm{Cu}$ and $\mathrm{Ni}$, respectively, results show that if both technical and non-technical criteria are adjusted by the relative importance of ions, chitosan (Alt1) scored highest (0.451), making it the best adsorbent to remove the three ions based on the estimates entered. On the other hand, if only technical criteria are adjusted by the relative importance of ions, sludge, with a score of 0.423 , is selected as the best alternative since it is the most readily available and cheapest adsorbent. If the relative importance of ions changed such that the scores of ions are $0.106,0.260$ and 0.633 for $\mathrm{Pb}, \mathrm{Cu}$ and $\mathrm{Ni}$, respectively, results show that if both technical and non-technical criteria are adjusted by the relative importance of ions, chitosan (Alt1) scored highest (0.381), making it the best adsorbent to remove the three ions based on estimated entries. But if only technical criteria are adjusted by the relative importance of ions, sludge, with a score of 0.452 , is selected as the best alternative since it is the most available and cheapest adsorbent. No change is suggested to final selection of adsorbent if all ions are considered equally important to be removed from wastewater.

When various combinations are considered, no change in results is observed given that technical criteria are considered slightly more important than non-technical criteria. If technical and non-technical criteria are equally important to the decision maker, results show that sludge (Alt3) scored highest using both methods of adjustment. The scores were 0.466 and 0.569 when both technical and non-technical are adjusted, and when only technical criteria are adjusted, respectively. If non-technical 


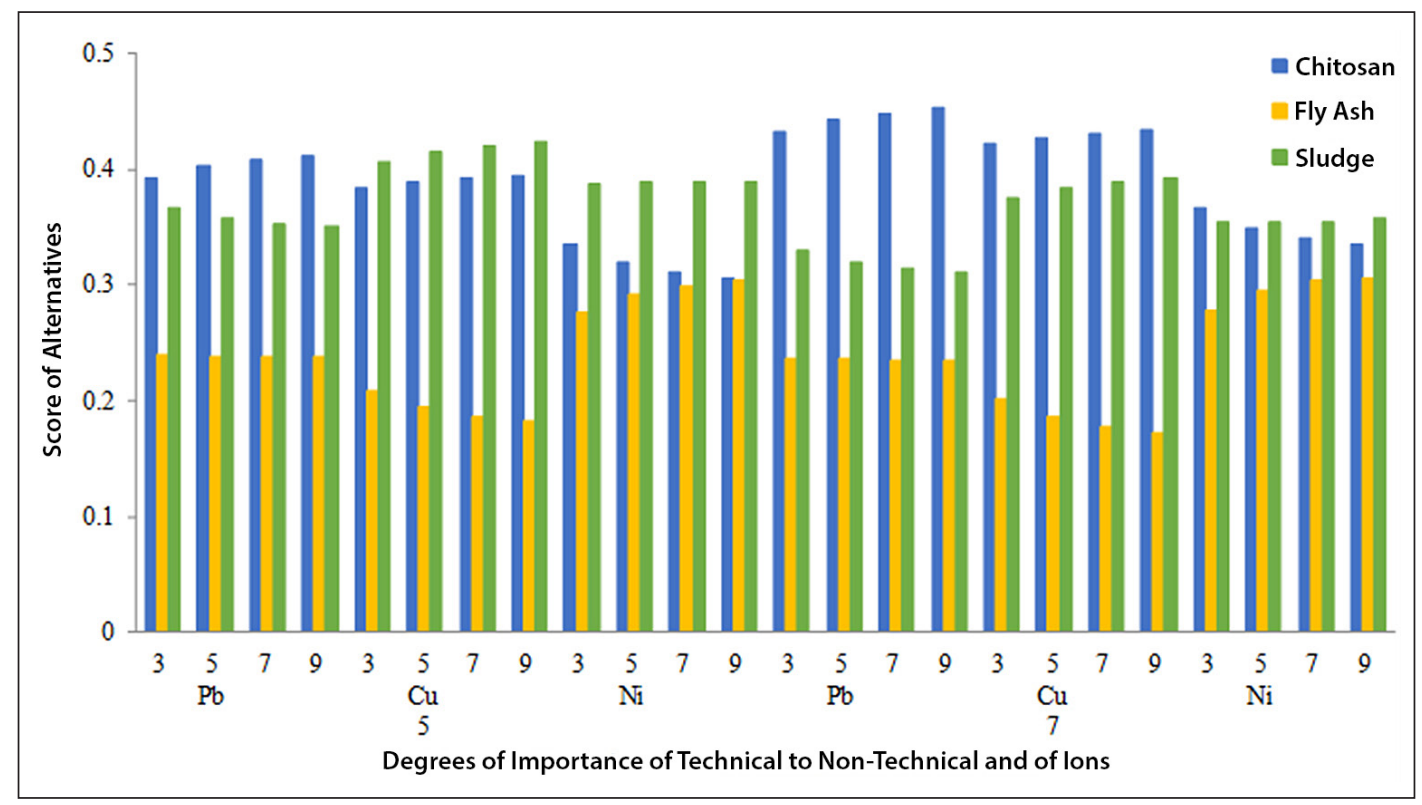

Figure 3. Summary of sensitivity analysis over various degrees of importance of main criteria and of ions, using Eq. 3 of adjustment

criteria are slightly more important to the decision maker than technical criteria, results show that sludge (Alt3) scored highest using both methods of adjustment, with scores of 0.569 and 0.631 , respectively. If non-technical criteria are absolutely more important to the decision maker than technical criteria, results show that chitosan (Alt1) scored highest using both methods of adjustment, with scores of 0.510 and 0.436 , respectively. If technical criteria are more important to the decision maker than non-technical criteria, results are similar to the original case where technical criteria are slightly more important than non-technical criteria. On the other hand, if technical criteria are strongly more important or are absolutely more important to the decision maker than non-technical criteria, results favour chitosan (Alt1) for the contamination with one type of ion. If technical criteria are more important than non-technical criteria and the scores for the importance of ions are $0.818,0.091$ and 0.091 for $\mathrm{Pb}, \mathrm{Cu}$ and $\mathrm{Ni}$, respectively, results show that chitosan (Alt1) is the best alternative for both adjustment methods. However, results favour chitosan (Alt1) using one adjustment method, and sludge (Alt3) using the other adjustment method, when the scores for ions are $0.091,0.091$ and 0.818 for $\mathrm{Pb}, \mathrm{Cu}$ and $\mathrm{Ni}$, respectively. Similar findings are obtained when the scores of ions are $0.091,0.818$ and 0.091 for $\mathrm{Pb}, \mathrm{Cu}$ and $\mathrm{Ni}$, respectively.

From the above discussion, one can note that results may vary significantly with a change in the methodology for adjusting the relative importance of technical and non-technical criteria. Moreover, changing the relative importance of ion types may change the final results when technical criteria are more important (Saaty of 5) or strongly more important (Saaty of 7) than non-technical criteria. Therefore, a detailed study of the effect of changing the degree of importance of each ion type is performed over the full range of the Saaty scale when technical criteria are more important (5) and strongly more important (7) than non-technical criteria. Figure 3 shows the change in the final selection among the adsorbents using Eq. 3 for adjustment. The figure reports the final scores of each adsorbent alternative for each type of ion being 3, 5, 7 and 9 times more important to be removed than the other two ion types.

\section{CONCLUSION}

This research presented a generic AHP-MCDM model for the highly technical problem of selecting a better adsorbent for the removal of several toxic metal ion types based on published experimental literature. The proposed model accounts for multiple ion types, technical and non-technical criteria and sub-criteria, and multiple adsorbent alternatives. Experimental findings reported in the literature were utilized to construct the pairwise comparison matrices of technical sub-criteria. A case study was constructed based on literature results for the removal of lead, copper and nickel ions using chitosan, fly ash and sludge adsorbents. Results show that decision makers need to control the $\mathrm{pH}$ level of wastewater and the dosage of adsorbent for better removal efficiency. Moreover, results from sensitivity analysis show that chitosan was the best adsorbent alternative based on its high technical qualities, and that the availability and low cost of sludge make it a strong alternative to choose if more weight is assigned to non-technical criteria. Furthermore, sensitivity analysis illustrates the direct impact of changing the relative importance of ions and the importance of technical criteria compared to non-technical criteria.

\section{REFERENCES}

ABDEL SALAM O, REIAD N and ELSHAFEI M (2011) A study of the removal characteristics of heavy metals from wastewater by lowcost adsorbents. J. Adv. Res. 2 297-303. https://doi.org/10.1016/j.jare. 2011.01.008

ABDEL-GHANI N and EL-CHAGHABY G (2014) Biosorption for metal ions removal from aqueous solutions: a review of recent studies. Int. J. Latest Res. Sci. Technol.324-42. https://pdfs.semanticscholar.org/ f5da/42e13c36f844ffa127333fccd6dffdaa5f71.pdf

AL-ZBOON K, AL-HARAHSHEH M and BANI HANI F (2011) Fly ash-based geopolymer for $\mathrm{Pb}$ removal from aqueous solution. J. Hazardous Mater. 188 414-442. https://doi.org/10.1016/j.jhazmat. 2011.01.133

ARIFFIN N, ABDULLAH M, ZAINOL M, MURSHED M, ZAIN H, FARIS M and BAYUAJI R (2017) Review on adsorption of heavy metal in wastewater by using geopolymer. In: Proceedings of the MATEC web of conferences, February 2017, Vietnam.

BISHT R, AGARWAL M and SINGH K (2016) Heavy metal removal from wastewater using various adsorbents: a review. J. Water Reuse Desalination 7 (4) 387-419. https://doi.org/10.2166/wrd.2016.104

BURAKOV A, BURAKOVA I, GALUNIN E and KUCHEROVA A (2018) New carbon nanomaterials for water purification from heavy metals. In: Martínez L, Kharissova O and Kharisov B (eds) Handbook of Ecomaterials. Springer International Publishing, New York.

CHANG C, WU C, LIN C and CHEN A (2007) An application of AHP and sensitivity analysis for selecting the best slicing machine. Comput. Ind. Eng. 52 296-307. https://doi.org/10.1016/ j.cie.2006.11.006 
FAROOQ U, KOZINSKI J, KHAN M and ATHAR M (2010) Biosorption of heavy metal ions using wheat based biosorbents - A review of the recent literature. Bioresour. Technol. 101 5043-5053. https://doi. org/10.1016/j.biortech.2010.02.030

HUI K, CHAO C and KOT S (2005) Removal of mixed heavy metal ions in wastewater by zeolite $4 \mathrm{~A}$ and residual products from recycled coal fly ash. J. Hazardous Mater. 127 (1-3) 89-101. https://doi.org/ 10.1016/j.jhazmat.2005.06.027

INYANG $\mathrm{M}$, GAO B, YAO Y, XUE Y, ZIMMERMAN A PULLAMMANAPPALLIL P and CAO X (2012) Removal of heavy metals from aqueous solution by biochars derived from anaerobically digested biomass. Bioresour. Technol. 110 50-56. https://doi.org/10.1016/j.biortech.2012.01.072

KAUR A and SHARMA S (2017) Removal of heavy metals from waste water by using various adsorbents- a review. Indian J. Sci. Technol. 10 (34). DOI: 10.17485/ijst/2017/v10i34/117269.
OMASA T, KISHIMOTO M, KAWASE M and YAGI K (2004) An attempt at decision making in tissue engineering: reactor evaluation using the analytic hierarchy process (AHP). Biochem. Eng. J. 20 173179. https://doi.org/10.1016/j.bej.2003.09.015

TURHANEN P, VEPSALAINEN J and PERANIEMI S (2015) Advanced material and approach for metal ions removal from aqueous solutions. Sci. Rep. 5 89-92. https://doi.org/10.1038/srep08992

VENKATARAMAIAH P, ROHITH $\mathrm{B}$ and MOHANAREDDY $\mathrm{P}$ (2012) Material selection for solar flat plate collectors using AHP. Int. J. Eng. Res. Appl. 2 1181-1185. https://pdfs.semanticscholar. org/106e/06ff611f1b9fe66ced6ce438785fa3e71ef7.pdf?_ga=2.508574 7.1636261565.1589836086-89022759.1569004712

YAVUZ O, ALTUNKAYNAK Y and GUZEL F (2003) Removal of copper, nickel, cobalt and manganese from aqueous solution by kaolinite. Water Res. 37 948-952. https://doi.org/10.1016/S00431354(02)00409-8 